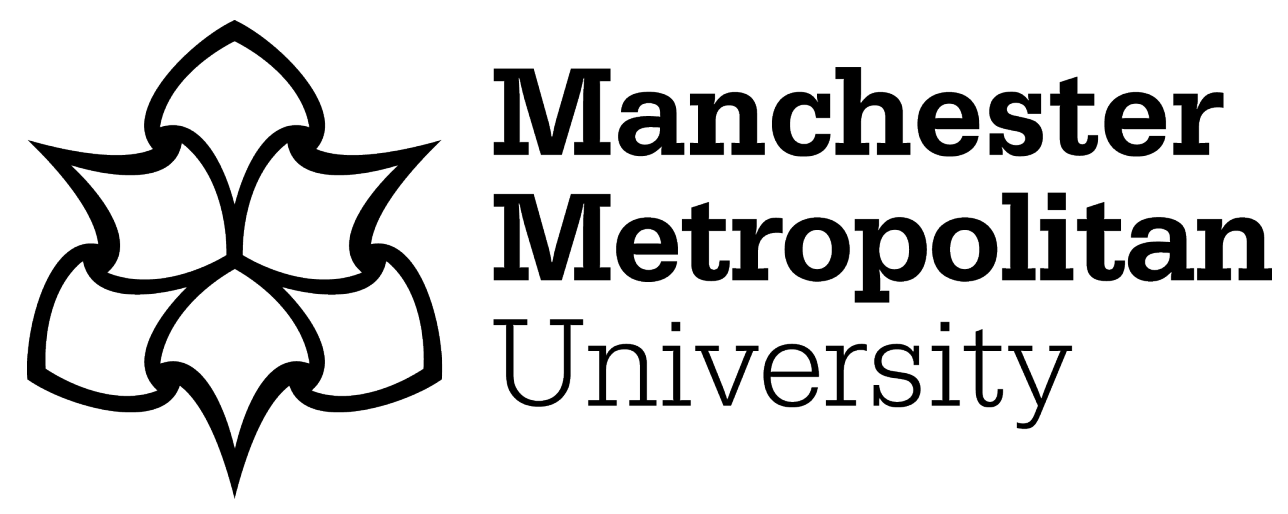

Savage, J ORCID logoORCID: https://orcid.org/0000-0002-2231-8357 (2012) Tom's story: developing music education with technology. Journal of Music, Technology and Education, 4 (2-3). pp. 217-226. ISSN 1752-7066

Downloaded from: https://e-space.mmu.ac.uk/288619/

Version: Accepted Version

Publisher: Intellect

DOI: https://doi.org/10.1386/jmte.4.2-3.217_1

Please cite the published version 


\title{
Tom's Story: Developing Music Education with Technology
}

\author{
Dr Jonathan Savage, Reader in Education, Institute of Education, MMU
}

\section{Introduction}

Tom, my fourteen year-old nephew was desperate to learn the guitar. My brother suggested a teacher, someone who would come around to the house once a week. Tom was excited, his enthusiasm contagious and a week later a young guitar teacher appeared at the door. The lessons lasted four weeks. Tom became bored, practised less and less, said he did not like the teacher or the music he wanted him to play, and most definitely wanted to bow out of the arrangement. His Dad was resigned to this being another one of those avenues that lead to a bit of a cul-de-sac, at least for the moment. He was sure Tom would find another to explore soon enough.

Six months later and, as I walked into my brother's house for a visit, I heard music coming from Tom's room. Good music. A guitar band with passable soloing and a steady groove. I wondered who it was. My brother told me to wander in. I found Tom plugged into his laptop, moving his eyes between a YouTube video and his guitar fret board. He had set up a system where he could slow down guitar parts to learn them more easily, he had accompanying drum and bass patterns to help him keep time, and he uploaded his practice sessions so that a group of his friends, having similar musical adventures, could hear what he was doing and leave comments. It was serious fun. Instead of one teacher a week coming round to the kitchen table, Tom was learning what he needed to know from YouTube videos and guitar forums.

Two months later and one of Tom's friends introduced him to ccMixter ${ }^{1}$. Now he began uploading his musical sketches and even complete songs. The other members on the site were able to download Tom's music, see what he had been doing in the online sequencer, overdub their own guitar parts, remix the song and share the result with the group. This remixing was infectious and multiple versions of Tom's songs began appearing. Perhaps the most important part of this though was the 'liking' system where Tom would receive 'likes' of his songs and comments left by other musicians. These were not his friends from school but musicians from all over the world. He was initially worried about being criticised for his offerings. However, he quickly noticed that there was an unwritten convention: 'no "slagging off"; when you come across something good, say that it is good.'

A musician who was remixing and overdubbing Tom's music more than any other, suggested that they get together online to 'jam'. They both looked around at various sites where they would be able to play together over the internet in real time. They found JamLink ${ }^{2}$ which allowed them to play, record, edit and mix their music. They uploaded the finished results to ccMixter where once again the community commented, downloaded, remixed and overdubbed.

Tom learned a whole host of different things in that time and with those tools, not least, how to learn from others and play with others.

\footnotetext{
1 http://ccmixter.com

2 http://www.musiclink.com
} 
These words, written by a colleague of mine, are, in one sense, unremarkable. Around the world, there are hundreds of thousands of young people like Tom learning to play musical instruments via the Internet. However, what is remarkable about Tom's story is the new way of learning that it illustrates. It takes place outside of institutions, without teachers, and without timetables. It is not what Tom learned but how he learnt that is most significant. He learned what he needed to when he needed to.

But perhaps the most significant learning that Tom experienced took place in the comments, exchanges, and remixes that he engaged in with his peer group. Some might think that such interaction online was cold and isolating. In reality, when Tom was with a teacher in the kitchen working his way through Ex. 6 from Book 1, he was more isolated than when he was involved in a social and cultural process online. The opportunity to participate, collaborate and interact enabled and deepened his learning through play, practice and experimentation. This often led to unplanned and innovative discoveries.

In stark contrast to the free-flowing, improvisatory nature of learning in the informal context of Tom's learning of the guitar, within formal educational settings the use of technology within music education seems, and is, more problematic. Here, many educational systems have failed to exploit the potential of these new technologies to the full. For example, within the United Kingdom the disjunction between these two worlds has been noted by many authors (Savage 2004, p.167; Cain 2004, p.217). It led OFSTED (the Government's agency for inspecting schools) to note that:

Music technology is changing rapidly and the schools found it difficult to develop their own resources in line with the quality of equipment which students were seeing - and sometimes using themselves - outside school. Consequently, ICT in school could appear dated to them. (Ofsted 2009, pp.34-35)

Within formal education, teachers often make uncritical responses to demands to increase the use of technology within music education. Students may be placed in front of computers working through activities that are un-musical, divorced from a meaningful context, with little sense of purpose and, on occasions, simply just a cover for a lack of effective teaching in basic musical skills. Over the last year, through visits to schools across the north of England, I have noted the following:

- Unskilful uses of music notation technologies to produce scores where considerations of instrumentation have been given cursory attention and instruments play at either impossible ranges or with little thought to specific instrumental techniques (bowing, phrasing, the requirement to breath, etc.);

- Insensitive and over-enthusiastic approaches to cutting and pasting in music sequencing software lead to compositions that have weak structures, lack of contrast and little, if any, melodic, harmonic or rhythmic variation and development;

- Creative 'borrowings' or 'samplings' of others' work through the opening of access to digital media being done with little thought to style, context, reinterpretation or ownership;

- An over-reliance on auto-accompaniments, auto-tuning or other supportive technologies for musical performance that provide cover (or an excuse) for the lack of rigorous teaching and training in basic musical skills (such as those required to play together in a group, or sing in tune). 
The challenge of writing a paper for a journal focussed on international perspectives of music education with technology got me thinking. In previous editions of this journal I have written about new instruments and technologies that I have developed, collaborations I have forged and reflected on the issues that these activities have raised. Since my last article (Savage 2010), my work has continued to move forward in various directions, some of which, I hope, would prove interesting to this audience.

However, the problem with any international focus is that it could pull towards a recounting of work in different countries with their unique set of cultural, sociological and historical contexts and, of course, there is nothing wrong with that in and of itself. Similarly, within the world of music education with technology, we are often very preoccupied with a particular context, tool or process. Journal articles often focus a particular project, piece of software development or specific piece of educational research. Again, these can result in fascinating studies.

Here, I want to take a different tack. It comes from my work over the last year with Tom's uncle, a colleague of mine working in another faculty at my university. Together, we have chatted, explored and written about educational processes with technology more generally. This work has resulted in a book to be published at the end of 2011 (McGoun \& Savage 2011). Over the year I have begun to see that education is framed by certain key ideas and technologies that are common to nearly every educational endeavour. Increasingly, I believe, these common influences will play a crucial part in any study of music education and, as you might expect, technology has a central role.

For me, Tom's story highlights four key ideas that we need to explore further. Each will drive future developments in music education with technology, pretty much regardless of international context. This paper will explore each, briefly, in turn before turning to some concluding comments. The four statements are:

1. The consummate power of the Internet;

2. Making (and learning) is connecting;

3. Caveat Emptor (buyer beware!);

4. Curriculum development is inextricably tied to teacher development.

\section{The Consummate Power of the Internet.}

The Internet is the most powerful technology available to us today. Tom's story shows the many potential benefits it can facilitate as a learning tool. More generally, research shows that many cognitive skills are substantially strengthened through its use, such as the strengthening of brain functions related to fast-paced problem solving, recognising patterns in a range of data and analysing their important characteristics, and making judgements about the quality of information contained within a particular source (Sillence et al 2007). Other studies have reported benefits in terms of small increases in working memory. These increases allow us to become more skilful in juggling ideas, focus our attention on competing ideas and analyse, almost instantaneously, their relative value. Small and Vorgan (2008, p.21) report that for many of us this has led to our 'developing neural circuitry that is customized for rapid and incisive spurts of direction attention'. Using the Internet also improves a range of lower-level skills such as hand-eye coordination (through various gaming environments), reflex response and the processing of visual cues (Green \& Bavelier 2003). 
Developmental psychologists have explored the effects of different types of media on peoples' intelligence and learning abilities. The conclusion of Greenfield's recent work (Greenfield 2009) starts with the obvious thought that each medium, each technology, develops a particular aspect of cognitive skill at the expense of others. So, what does she have to say about the Internet? Her research indicates that the growing use of the Internet has led to a 'widespread and sophisticated development of visual-spatial skills'. But there is the trade-off. Greenfield suggests that the new strengths in visual-spatial intelligence goes 'hand in hand with a weakening of our capacities for the kind of 'deep processing' that underpins mindful knowledge acquisition, inductive analysis, critical thinking, imagination and reflection' (ibid, p.52).

Given findings such as these, writers like Nicholas Carr have argued that whilst:

... the Net grants us instant access to a library of information unprecedented in its size and scope, and it makes it easy for us to sort through that library ... what the Net diminishes is [Johnson's] primary kind of knowledge: the ability to know, in depth, a subject for ourselves, to construct within our own minds the rich and idiosyncratic set of connections that give rise to a singular intelligence. (Carr 2010, p.143

The tools that we choose to use for our work impose limitations as well as open possibilities. 'We shape our tools' observed Culkin (1967), 'and thereafter they shape us'. Music teaching and learning will increasingly be situated within the Internet's domain. Tom's story gives a clear illustration of this occurring already. Music education research needs to focus on the consuming power of the Internet and document its affect on teaching and learning processes.

But Tom's story hints at a specific feature of the Internet that we need to acknowledge and examine further in our research into new approaches for music teaching and learning. Learning is increasingly becoming a social rather than an individual practice. This leads to my second key statement drawn from Tom's story.

\section{Making (and Learning) is Connecting.}

Tom's story is built around the facilitate power of the Internet to connect people in different ways. His learning, the construction of his abilities to play the guitar effectively on his own and with others, took place within that new, collaborative learning environment. Gauntlett's book (2011) argues that making has always been about connecting people. Whilst he recognises that many writers and thinkers have located creativity within the context of the individual human mind and its capacity to think and develop new thoughts, his broader analysis of what creativity is ties up with the concept of making. So, early in his book, he argues that creative people engage in making, but that this making is in fact part of the same process of connecting with others. How? He summarises it in three ways:

- Making is connecting because you have to connect things together (materials, ideas or both) to make something new;

- Making is connecting because acts of creativity usually involve, at some point, a social dimension and connect us with other people;

- And making is connecting because through making things and sharing them in the world, we increase our engagement and communication with our social and physical environments. (ibid, p.2). 
For us, as musicians and educators, there is an enjoyable sense of metaphorical play here. Making is central to our practice as musicians; but making can also be transposed to the context of learning and teaching, whether it become part of a process of constructing knowledge, engaging in a shared journey of enquiry or a creative endeavour. However we conceptualise it, making and learning are (and always has been) about connecting. Substitute the word 'learning' for 'making' in the above three bullet points and you will see what I mean.

Moving from a position in which learning has been dominated by the 'individual' mind or body, today, in the experiences of many working across a huge range of contexts, learning is becoming something that is collaborative and communal, not easily reduced to internalised, individual cognitive processes.

Learning is socialised. Similarly, making and learning in music education should be infused by a sense of connectedness (whether it be about musical performance, composition or listening). Music is a social practice. Music education needs to rediscover it social dimension.

The implications of these statement for our work as music educators within formal education are profound. It helps explain the huge popularity of social media platforms that many young people inhabit today. Gauntlett's book goes on to examine in significantly more detail the consequences of such engagements. These are summarised as:

- A new understanding of creativity as process, emotion and presence;

- The drive to make and share;

- Happiness through creativity and community;

- A middle layer of creativity as social glue

- Making your mark, and making the world your own.

Many of these characteristics can be found in Tom's story. They lead to an obvious question: do teachers have a role to play anymore? For Tom, a formal guitar teacher was not required. But should that always be the case?

\section{Caveat Emptor (Buyer beware!)}

Tom's story does not cast the teacher in a good light. The failure of his guitar teacher led him to find alternatives, to reject the teacher completely, and utilise the potential of the Internet as a social, collaborative learning environment. In previous generations, perhaps Tom would have given up completely. Today, he learnt to play the guitar. However, would he have learnt more, and perhaps become a more proficient guitarist, if he had the benefit of both?

Arendt, much more eloquently, puts it like this:

Education is the point at which we decide whether we love the world enough to assume responsibility for it and by the same token save it from ruin which, except for renewal, except for the coming of the new and young, would be inevitable. And education, too, is where we decide whether we love our children enough not to expel them from our world and leave them to their own devices, nor to strike from their hands their chance of undertaking something new, something unforeseen by us, but to prepare them in advance for the task of renewing a common world. (Arendt 1961, p.196) 
Arendt's words are as relevant today as they were in 1961. Note the responsibility placed on the role of teachers to make decisions on behalf of their pupils and to make these decisions based on their care for them as children. Central to Arendt's thesis is the notion that teachers have access to knowledge and ideas which their pupils do not have and that they know something about the best way to introduce these things. But, also notice that she suggests that there are things that are, as yet, unforeseen by children and teachers. Neither group can predict the futures that these children will face, the new jobs and opportunities it might contain, or the types of practical skills or understanding they will need to succeed. However, teachers do know, Arendt says, that we can prepare children for those future tasks through a careful exemplification and study of the world as it is today. She argued that pupils are best prepared for their future lives by teachers who educate them to understand the world that we know. Or, in Furedi's words, 'there is a need to preserve the past for the sake of the new' (Furedi 2009, p.42).

These thoughts are particularly acute when faced with digital technologies. Firstly, for many, technology is explicitly linked to the new. We might suggest, from Arendt's perspective, that becoming overly preoccupied with the new is a dangerous position for educators. Secondly, Arendt highly values the knowledge that we have as adults and suggests that teachers should value this and use it wisely. Whilst young people are curious about technology and quick to use it in new and imaginative ways, there is not an automatic reason why this should cause us to embrace their new approaches and use them within formal education. There may be good reasons for doing so; but there may be even better reasons for holding back on occasions.

Within music education specifically, and as our discussion about the role of the Internet in Tom's learning above briefly considered, technologies impose limitations as well as open up possibilities. Part of the key here is choosing technologies that are appropriate to the tasks at hand and use them skilfully, with full knowledge of both the up and downsides. The 'numbing' affect of technology has been well documented. Carr, drawing on Marshall McLuhan, writes:

When we extend some part of ourselves artificially, we also distance ourselves from the amplified part and its natural functions. When the power loom was invented, weavers could manufacture far more cloth during the course of a workday that they'd been able to make by hand, but they sacrificed some of their manual dexterity, not to mention some of their 'feel' for the fabric. Their fingers, in McLuhan's terms, become numb. (Carr 2010, p.210)

This physical numbing is highly dangerous for music education. But it does not end there. What is true for the fingers is true for the mind and the ear too. Illustrations like these should warn us against being too positive or celebratory about the potential benefits of using any one piece of technology within music education. In my experience, whilst it is often easy to see the potential benefits of bringing a new piece of technology into a classroom, the downside of any piece of technology, in both physical, cognitive and musicological aspects, are often identified and analysed less readily by many teachers or researchers.

So, whilst it is important for us to be aware of what the latest technological developments are, it is by no means an automatic assumption that they are going to be appropriate or desirable for teaching and learning. One area in which this debate has played out in recent years has concerned the use of mobile phones within schools. The disconnect between young peoples' extensive use of mobile technologies outside of school when compared to 
their use within schools demonstrates an interesting aspect of power in relation to choice. Many schools seem happy to reject the technology itself (i.e. through banning the use of mobile-phones in lessons), whilst completely ignoring the wider cultural, cognitive and neurological affects that having access to these technologies in young peoples' wider lives have facilitated.

In one sense, the argument is not just about the technology itself and whose choice wins the day. Carr's analysis indicates that the numbing affect of technology leads to alienation:

\begin{abstract}
Alienation is an inevitable by-product of the use of technology. Whenever we use a tool to exert greater control over the outside world, we change our relationship with that world. ... In some cases, alienation is precisely what gives a tool its value. We build houses and sew Gore-Tex jackets because we want to be alienated from the wind and the rain and the cold. ... An honest appraisal of any new technology, or of progress in general, requires a sensitivity to what's lost as well as what's gained. We shouldn't allow the glories of technology to blind our inner watchdog to the possibility that we've numbed an essential part of our self. (Carr 2010, p.212)
\end{abstract}

As teachers, whether the choice of a piece of technology comes from our own understanding, or whether it relates to a technology that is situated in the wider lives of young people, it is essential that our analysis of that tool and its use for educational purposes is carried out rigorously and conscientiously. This is a vital dimension that any future research in the field of music education with technology should start with. It leads onto my concluding statement.

\title{
4. Curriculum development is inextricably tied to teacher development.
}

One of my educational heroes, Lawrence Stenhouse, had a key phrase that he used, on many occasions, to summarise his work: there is no curriculum development without teacher development. As we have seen, Tom's story is one of teacher failure and learner autonomy. From Tom's perspective, there are degrees of success and empowerment there. But there are other stories that can be told. Stories within which teachers play a positive, facilitating role in their pupils' music education. Stories in which teachers make wise choices about the resources they use with their pupils, the structures within which their pupils' learning occurs, and the links they make to their pupils' wider musical lives and experiences outside the school. Teachers have a vital and skilful role to play in the provision of high quality music education for every child.

Within the United Kingdom, this teacher-led provision is under threat. Here, as the result of a range of hastily implemented educational policies, music, alongside other arts and humanities subjects, are being side-lined in many of our schools. But more widely, across the globe, there are similar trends. On the 5th April 2011, the Fellows of the Salzburg Global Seminar met to discuss the future of music education. Fifty four eminent musicians, writers, scientists and thinkers (including people like Nicholas Kenyon, Graham Welch and Martin Neary) agreed on the instrumental value and transformative power of music, but their manifesto ('The Value of Music: The Right to Play) contained a darker theme. Part of it read:

The future of music education is at risk. Our youth deserves an immediate commitment to music as part of the core education curriculum. (Salzburg Global Seminar 2011)

The development of a rich, varied, broad and balanced curriculum and the skilful, 
professional role that teachers play in delivering this are inextricably linked. As researchers, our work must seek to empower and equip those that teach with the appropriate knowledge and understanding for a coherent music education provision facilitated through a comprehensive understanding of the risks and benefits of technology and the social interaction that it promotes. As teachers, we have a responsibility not to fail young people like Tom.

\section{References}

Arendt, H. (1961) Between Past and Future. Six exercises in political thought. London, Faber \& Faber.

Cain, T. (2004) 'Theory, technology and the music curriculum'. British Journal of Music Education 21:2, pp.215-221.

Carr, N. G. (2010) The Shallows: What the Internet is doing to our brains. New York, W.W. Norton.

Culkin, J. (1967) 'A Schoolman's Guide to Marshall McLuhan'. The Saturday Review.

Furedi, F. (2009) Wasted: Why education isn't educating. London, Continuum.

Green, C. S. \& Bavelier, D. (2003). 'Action video game modifies visual selective attention. Nature, 423, 534-7.

Gaunlett, D. (2011) Making is Connecting: The social meaning of creativity, from DIY and knitting to YouTube and Web 2.0. Cambridge, Polity.

Greenfield, P. M. (2009) 'Technology and informal education: What is taught, what is learned'. Science Science, 323, 69-71.

McGoun, C. \& Savage, J. (2011) Teaching Contemporary Themes in Secondary Education: Technology, Culture and Communication. London, Routledge.

Ofsted (2009) Making More of Music. London, Ofsted. Also available from: http:// www.ofsted.gov.uk/Ofsted-home/Publications-and-research/Browse-all-by/Documents-bytype/Thematic-reports/Making-more-of-music-an-evaluation-of-music-in-schools-2005-08 [last accessed 1/12/10].

Salzburg Global Seminar (2011) The Right To Play. Also available from: http:// www.salzburgglobal.org/current/News.cfm?IDMedia=60456 [last accessed 12/9/11].

Savage, J. (2010) 'Hand2Hand and Dot2Dot: Developing instruments for the music classroom'. Journal of Music, Technology and Education, 2:3, 141-158.

Savage, J. (2004) 'Working Towards a Theory for Music Technologies in the Classroom: How students engage with and organise sounds with new technologies'. British Journal of Music Education 22:2, pp.167-180.

Sillence, E., Briggs, P., Harris, P. R. \& Fishwick, L. (2007) 'How do patients evaluate and 
make use of online health information?' Social Science and Medicine, 64, 1853-1862.

Small, G. W. \& Vorgan, G. (2008) Ibrain: Surviving the technological alteration of the modern mind. New York, Collins Living.

4251 words 